\title{
Challenging Breast Reconstruction after Excision of Giant Phyllodes Tumor with the Largest Ever Reported Soft Tissue Defect
}

\author{
Ahmad Ibrahim Yahaya ${ }^{1 *}$, Lee Shi Zhen ${ }^{2}$, Ahmad Ibrahim Ahmad Zaidi ${ }^{2}$, Izety Shezlinda Noran ${ }^{2}$
}

${ }^{1}$ MBBCh (Cairo), Department of General Surgery, Hospital Melaka, Jalan Mufti Haji Khalil, 75400 Melaka, Malaysia

${ }^{2}$ MS Plastic Surgery (USM), Department of Plastic and Reconstructive Surgery, Hospital Melaka, Jalan Mufti Haji Khalil, 75400 Melaka, Malaysia

DOI: $10.36347 /$ sjmcr.2020.v08i09.014

| Received: 13.09.2020 | Accepted: 21.09.2020 | Published: 24.09.2020

*Corresponding author: Ahmad Ibrahim Yahaya

Abstract

Case Report

Giant phyllodes tumors (PT) are those measuring more than ten centimeters. To date, there are eight cases of giant PT treated with mastectomy and breast reconstruction (BR) reported in the English literature. Almost all reports focused on the tumor size rather than the chest wall tissue defect size after tumor extirpation. While mastectomy is almost inevitable in all giant PT's, none of the previously reported cases discussed on the impact of PT to the patient's psychology and quality of life (QOL). We report a challenging giant PT case with the largest chest wall defect ever reported so far, treated with mastectomy and BR, with good cosmetic and psychological outcomes.

Keywords: Giant phyllodes, TRAM flap, vascular delay, quality of life, SF-36.

Copyright @ 2020: This is an open-access article distributed under the terms of the Creative Commons Attribution license which permits unrestricted use, distribution, and reproduction in any medium for non-commercial use (NonCommercial, or CC-BY-NC) provided the original author and source are credited.

\section{INTRODUCTION}

Phyllodes tumor (PT) is a rare fibroepithelial neoplasm arising from periductal stroma of the breast and those measuring more than ten centimeters are called giant PT [1]. While surgical resection is the mainstay of PT treatment, surgeons often face challenges in soft tissue coverage after tumor extirpation.

\section{Case Report}

A 51 year-old lady presented with a gradually increasing right breast swelling for five years. On examination, there was a huge mass occupying the whole right breast measuring 40x40cm (Figure-1a). Per abdomen, 20 weeks size uterus was palpable. She was obese with a body mass index (BMI) of $35 \mathrm{~kg} / \mathrm{m}^{2}$.

Histopathological examination (HPE) of the lesion was suggestive of phyllodes tumor. Computed tomography scan of thorax, abdomen and pelvis revealed a large right breast mass with local mass effect without distant metastasis, and uterine fibromata.

Taking into account the potential huge chest wall defect after tumor excision, the need for larger flap skin paddle, large uterus risking the donor site closure to be under tension, and obesity, the operation performed was right mastectomy with immediate breast reconstruction (BR) using delayed bipedicled
Transverse Rectus Abdominis myocutaneous (TRAM) flap, total abdominal hysterectomy bilateral salphingooophorectomy (TAHBSO), prophylactic appendicectomy and polypropylene mesh implant.

Intra-operatively, the right breast tumor was $53 \times 37 \times 17 \mathrm{~cm}$ (Figure-1b), the final defect was $35 \times 26 \mathrm{~cm}$ (Figure-2a) and the skin paddle was $20 \times 12 \mathrm{~cm}$ (Figure$2 b)$ in size.

Ex-vivo tumor size was $30 \times 24.5 \times 15.5 \mathrm{~cm}$ weighing $6.7 \mathrm{~kg}$. HPE confirmed the tumor as benign phyllodes. Post-operatively the flap survived $100 \%$ but wound dehiscence developed at the flap donor site requiring debridement, negative pressure wound therapy and delayed primary closure. 12 months followup showed no ventral hernia or recurrence, with good breast mound whereby patient can wear her original undergarment comfortably (Figure-3).

Medical Outcome 36-item Short Form (SF-36) assessment showed great improvement in all domains post-operatively as compared to pre-operation. Preoperative SF-36 assessment showed low score (less than $30 \%$ ) in all eight domains, with zero percent in role limitation due to physical problems, role limitation due to emotional problems and social functioning. 12 months post-operatively, SF-36 assessment showed a score of $96 \%$ for emotional well-being domain, $90 \%$ for bodily pain domain, while the other six domains scored $100 \%$. 


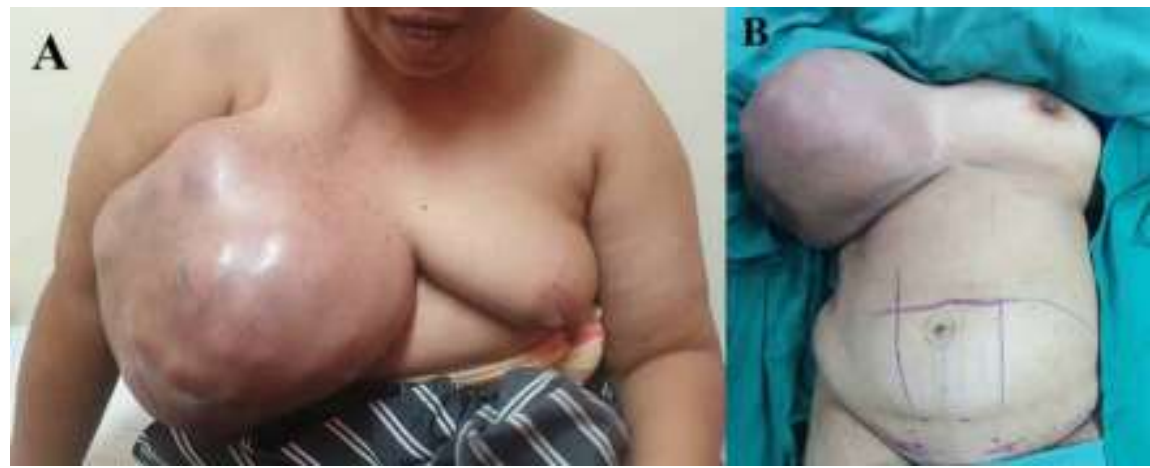

Fig-1: A\&B: Pre-operative images

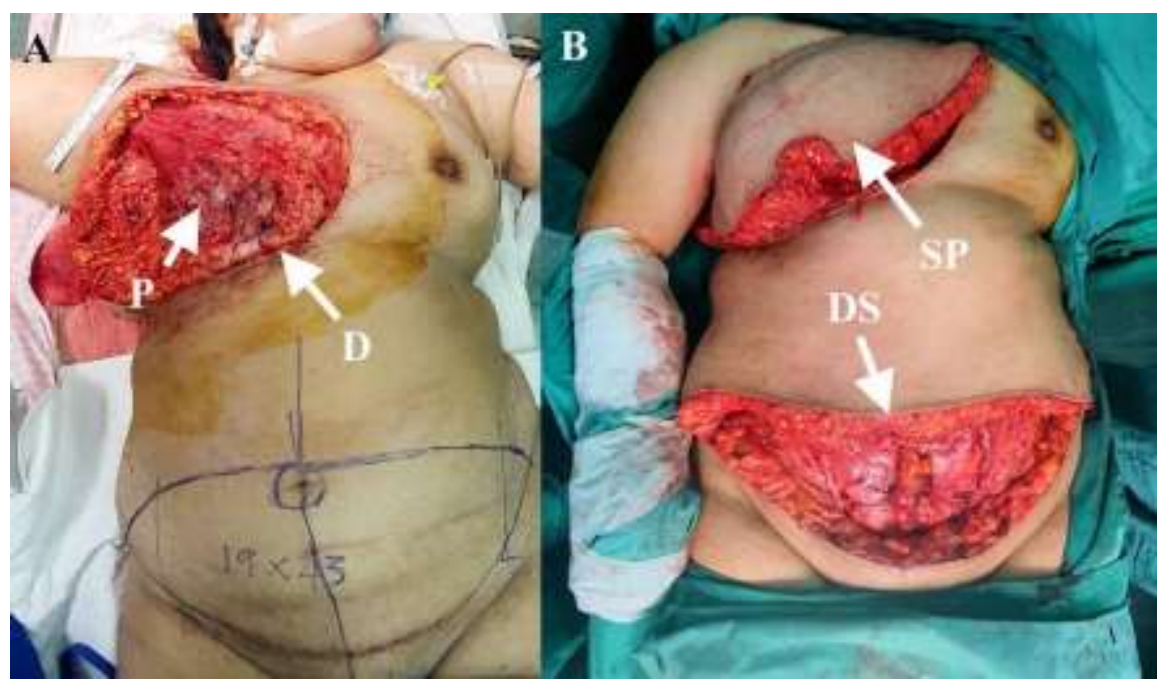

Fig-2: A: Intra-operative image showing; D-soft tissue defect, P-Pectoralis Major muscle. B: Intra-operative image showing; DS-donor site, SP-skin paddle

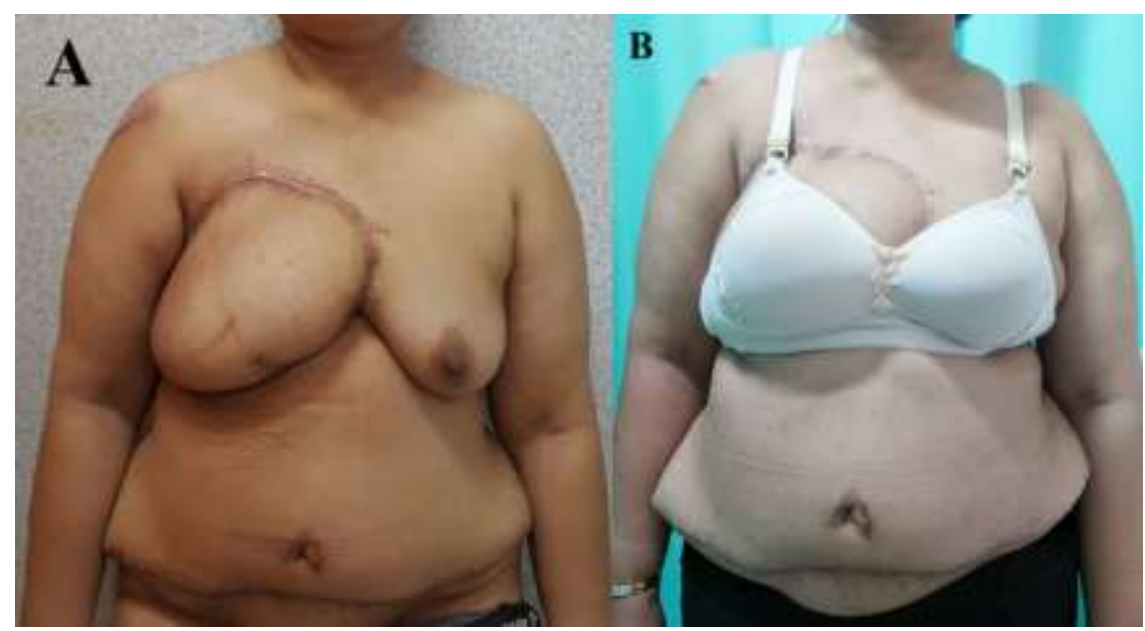

Fig-3: A: Post-operative outcome at 2 months. B: 6 months; patient on her undergarment (original pre-operative size)

Table-1: Summary of eight reported cases of giant PT treated with BR in English literature.

\begin{tabular}{|l|l|l|l|}
\hline Authors & Tumor maximum diameter $\mathbf{~ ( c m ) ~}$ & Defect size $\mathbf{( c m})$ & Flap Type \\
\hline Islam S et al., $[9]$ & 50 & - & Latissimus Dorsi (LD) \\
\hline C. Walravens et al., [1] & 38 & - & Pedicled TRAM \\
\hline Sarvanandan et al., $[10]$ & 28 & - & LD \\
\hline Pitsinis et al., [11] & 20 & - & DIEP \\
\hline Tsuruta et al., [3] & 19.9 & $22 \times 24$ & DIEP \\
\hline Tu et al., $[4]$ & 16 & $18 \times 15$ & DIEP \\
\hline Moon et al.., [12] & 15.5 & - & Thoracoabdominal \\
\hline Pitsinis et al., $[11]$ & 14 & - & LD \\
\hline
\end{tabular}




\section{DISCUSSION}

Primary closure after mastectomy for a giant PT is still possible regardless of size [2]. The largest PT reported, with maximum diameter of $60 \mathrm{~cm}$ was managed by mastectomy and primary closure [2]. This proves that the tumor size is not the only factor imposing technical challenges to the surgeons and decision for BR.

To date, there are eight cases of giant PT treated with mastectomy and BR reported in the English literature (Table-1). While almost all reports focused on the tumor size, only two reports documented the soft tissue defect size after tumor extirpation [3,4]. This is in fact an important aspect which determines the feasibility of primary closure.

Our case had a soft tissue defect of $35 \times 26 \mathrm{~cm}$, the largest ever reported so far. The tumor base incorporated a wide area of chest wall making primary closure impossible, hence tissue coverage is mandatory. TAHBSO was necessary to allow abdominal wall closure with less tension. Two weeks prior to TRAM flap BR, the patient underwent bilateral Deep Inferior Epigastric Artery (DIEP) ligation as vascular delay procedure to reduce ischemia-related complications of flap.

Breast is an important organ to women for which loss of whole or part of it is traumatizing. Psychosocial morbidity (anxiety, depression, body image, sexuality and self-esteem) are significantly lower in mastectomy with BR compared to mastectomy only [5], as shown in our case.

For those reasons, excision with BR, although more demanding in many aspects (technical difficulty of the surgery, complications, tedious monitoring), is advocated by many authors for optimal cosmetic and psychological outcome, contributing to better QOL after surgery.

There are various types of flap for autologous BR. Evaluation and selection of patients for the suitable type of flap is important [6]. Abdomen is the major source of flap for BR due to tissue availability and skin color. The two BR workhorse flaps are LD and TRAM. Both techniques have satisfactory result and there were no significant differences in the morbidity [7]. Hence, the selection of flap technique should be based on evaluation of anatomy, breast volume requirements and donor site considerations [6].

TRAM flap BR is a reliable technique, but ischemia-related complications were reported to occur in $5-28 \%$ of cases. The rate of complications such as fat necrosis and partial flap loss are higher in patients with risk factors including obesity, cigarette smoking, radiation and abdominal scars [8].
For this reason, vascular delay procedure is advocated to reduce ischemia-related complications of TRAM flap BR. It is done by ligating the DIEA two weeks before the TRAM flap BR. This will cause flow augmentation of reduced-caliber choke vessels, reversal of flow across regurgitant valves and formation of collateral flow, which will improve flap reliability and increase nutrient blood flow [8]. Our patient has one risk factor (obesity), hence we opted vascular delay procedure. The flap survived $100 \%$ with good cosmetic and psychological outcomes.

\section{Conclusion}

Managing a giant PT is challenging. Methods of surgical treatment should be based on the tissue defect rather than tumor size alone. BR contributes to better quality of life. Hence surgeons should discuss BR options with patients not only in case where the defect is impossible to close.

\section{ACKNOWLEDGEMENT}

We would like to acknowledge the Director General of Health Malaysia for his permission to publish this article. We would like to offer our special thanks to Dr. Nanthini Ponnuvelu and Dr. Sim Chien Chuen from the Department of General Surgery Hospital Melaka, Malaysia, Dr. Tham Seng Who, consultant gynecologist Hospital Melaka, all doctors and staffs of the Department of Plastic and Reconstructive Surgery Hospital Melaka, the Department of General Surgery Hospital Melaka, and the Pink Ribbon Center Melaka for their contributions in the patient's management and their assistance in the data collection. The valuable images of the case were provided by Dr. Izety Shezlinda Noran, Dr Ahmad Ibrahim Yahaya and Dr Amirah A.

Consent: Written informed consent was obtained from the patient for publication of this case report and accompanying images.

Conflict of Interest \& Financial Disclosure: There is no conflict of interest or any financial support involved in this case report.

\section{REFERENCE}

1. Walravens C, De Greef C. Giant phyllodes tumour of the breast. Journal of Plastic, Reconstructive \& Aesthetic Surgery. 2008 Oct 1; 61(10):e9-11.

2. Zayen S, Amouri H, Dhouib M, Trigui D, Ayed BB, Guermazi M. Giant phyllodes tumor of the breast: consequence of carelessness. Acta Oncologica. 2011 Apr 1; 50(3):468-70.

3. Tsuruta Y, Karakawa R, Majima K, Yamamoto S, Shibata T, Yoshimatsu H, Miyashita H, Tanakura $\mathrm{K}$, Yano $\mathrm{T}$. The reconstruction after a giant phyllodes tumor resection using a DIEP flap. 
Plastic and Reconstructive Surgery Global Open. 2020 Apr; 8(4).

4. Tu CW, Fang CL, Tsai CB, Hsu CH, Changchien $\mathrm{CH}$, Chen MS. Breast reconstruction after resection of bilateral giant phyllodes tumors: two separate deep inferior epigastric perforator flaps from one donor site. Clinical Breast Cancer. 2020 Apr;20(2):e188-91.

5. Al-Ghazal SK, Fallowfield L, Blamey RW. Comparison of psychological aspects and patient satisfaction following breast conserving surgery, simple mastectomy and breast reconstruction. European Journal of Cancer. 2000 Oct 1; 36(15):1938-43.

6. Wei and Mardini. Maurice Y. Nahabedian. Breast Reconstruction. In. Wei FC, Mardini S. Flaps and reconstructive surgery. $2^{\text {nd }}$ Edition. New York; Elsevier Inc; 2017; 183-200.

7. Galli A, Raposio E, Santi P. Reconstruction of full-thickness defects of the thoracic wall by myocutaneous flap transfer: latissimus dorsi compared with transverse rectus abdominis. Scandinavian Journal of Plastic and Reconstructive Surgery and Hand Surgery. 1995 Jan 1; 29(1):39-43.
8. Codner MA, Bostwick 3rd J, Nahai F, Bried JT, Eaves FF. TRAM flap vascular delay for high-risk breast reconstruction. Plastic and Reconstructive Surgery. 1995 Dec 1; 96(7):1615-22.

9. Islam S, Shah J, Harnarayan P, Naraynsingh V. The largest and neglected giant phyllodes tumor of the breast - a case report and literature review. International Journal of Surgery Case Reports. 2016 Jan 1; 26:96-100.

10. Sarvanandan R, Thangaratnam R, Leong AC. Immediate latissimus dorsi pedicle flap reconstruction following the removal of an eight kilogram giant phyllodes tumour of the breast: a case report. Journal of Medical Case Reports. 2011 Dec;5(1):1-6.

11. Pitsinis V, Moussa O, Hogg F, McCaskill J. Reconstructive and oncoplastic surgery for giant phyllodes tumors: a single center's experience. World Journal of Plastic Surgery. 2017 May; 6(2):233.

12. Moon SH, Jung JH, Lee J, Kim WW, Park HY, Lee JW, Lee SJ. Complete remission of giant malignant phyllodes tumor with lung metastasis: a case report. Medicine. 2019 May; 98(22). 